\title{
Article
}

\section{COVID-19: The Culprit, the People and Lessons Learned}

Kayihura Manigaba, PharmD, BCIDP, ${ }^{1}$ Mukundwa K Gael ${ }^{2}$

\section{Abstract}

\section{Description}

COVID-19 has had a palpable impact on everyone from losing jobs to losing loved ones. It has altered our social dynamics and disturbed the world economy. We should all learn something from this challenging time. This article elaborates on three lessons learned by two brothers who grew up in Rwanda right after the 1994 genocide against the Tutsi, where more than one million people died in 100 days. One, Dr. Kayihura Manigaba, is currently responding to the COVID-19 pandemic as a clinical pharmacy manager and as an infectious diseases pharmacy specialist at a hospital in Florida, U.S, and the other, Mukundwa Gael, is finishing his pharmacy doctorate training in Tennessee, U.S.

Author affiliations are listed at the end of this article.

Correspondence to:

Kayihura Manigaba, PharmD, BCIDP

Clinical Pharmacy Manager North Florida Regional

Medical Center

6500 W Newberry Rd

Gainesville, FL 32605

(Kayihura.manigaba@gmail. com)

Every year, on average, three new human pathogen species are discovered in different geographical locations, and the majority of them are viruses. This implies that we will continve to face crisis secondary to a new microbe, and we have no idea where it will begin and whether the community of origin will be capable of containing it from reaching the rest of the world. In this paper, the authors emphasize the importance of collaboration in identifying, preventing, and treating health threats.

In addition to sharing lessons such as the impact of fear on crisis response, and how to rise to the occasion during a crisis, the authors intend to motivate readers to believe in their unique skills that are needed to advance our society as we define our new world during and post COVID-19 pandemic.

\section{Keywords}

COVID-19; coronavirus infections; SARS-CoV-2; healthcare disparities; resilience; collaboration; empathy; fear; crisis; pandemic

\section{Introduction}

Coronavirus Disease 2019 (COVID-19) has had a palpable impact on our lives, from losing jobs to losing loved ones. We have seen it freeze the world economy and alter our social dynamics. We should all learn something from this challenging time. We would like to share three lessons learned by two brothers who grew up in Rwanda right after the 1994 genocide against the Tutsi, where more than one million people died in 100 days. One, Dr. Kayihura Manigaba, is currently responding to the COVID-19 pandemic as a clinical pharmacy manager and as an infectious diseases pharmacy specialist at a hospital in Florida, United States (U.S.), and the other, Mukundwa Gael, is finishing his phar- macy doctorate training in Tennessee, U.S.

The emergence of the new coronavirus (SARSCoV-2) that spread to the rest of the world has reminded us that no community or country is impervious to suffering. This disease is highlighting global health disparities and the need to work together in identifying, preventing, and treating health threats. How many outbreaks have happened in other communities or countries, and the first concern we had was the possibility of reaching our communities? When the large-scale 2014-2016 Ebola outbreak hit West Africa, what was the main fear of those living in non-affected regions? Are we equally concerned about malaria as it disproportionately

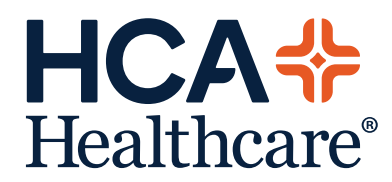

www.hcahealthcarejournal.com

(C) 2020 HCA Physician Services, Inc. d/b/a Emerald Medical Education

\author{
HCA Healthcare \\ Journal of Medicine
}


claims lives in the sub-Saharan countries?

\section{The Culprit: "It's Their Problem" Syndrome}

In late 2019, COVID-19 was regarded mainly as a health threat to China. In March 2020, it was evident to most people in the world that COVID-19 was no longer "their problem." We say "most" because during this pandemic, some people still held the mentality that it only affects the elderly population, or those who are immunocompromised. We saw pictures in the media of people gathering and flocking to the beaches during spring break in the U.S., despite recommendations to avoid public gatherings. The world is collectively suffering from "it's their problem" syndrome. This syndrome is slowly destroying humanity.

There are examples in the past where the "it's their problem" mentality cost millions of lives, and where international collaborative efforts saved many. In 1994, millions of Rwandan lives were lost during the genocide against the Tutsi while the world watched from afar, believing it was a problem for the Rwandans., ${ }^{1,2}$ On the other hand, when Ebola cases started to emerge in the U.S., the Centers for Disease Control and Prevention (CDC) responded by training healthcare workers in the affected West Africa region, which helped to contain and prevent further spreading. ${ }^{3}$ For the world to heal from "it's their problem" syndrome, we need selfless actions from everyone with the sole intention of alleviating other people's suffering.

\section{The People: We Are in This}

\section{Together}

Every year, on average, three new human pathogen species are discovered in different geographical locations, and the majority of them are viruses. ${ }^{4}$ This signifies that from time to time, we are going to face a crisis secondary to a new microbe. We have no idea where it will begin and whether the community of origin will be capable of containing it from reaching the rest of the world. As a society, we are prone to natural health threats such as COVID-19, and working together is not optional but a mandatory responsibility for humanity. No one should sit back and wait to give others a pat on the back as they finish their struggle. We should reach out to one another and lend a hand. In the words of the great Dr. Martin Luther King Jr., "In the end, we will remember not the words of our enemies, but the silence of our friends."

\section{Lessons Learned: Rise Together Without Fear \\ Lesson number 1: Fear can worsen our response to a crisis}

It is human nature to be afraid of the unknown. The early phase of the COVID-19 pandemic was nothing short of unknowns. When we learned that the virus would likely arrive in our communities, fear suddenly took over as a driving force in survival decisions, and the world suffered collateral damage stemming from fear-based actions. Basic protective gear such as N-95 masks suddenly disappeared from the marketplace. Everyone agrees that health care personnel taking care of patients with this contagious virus should not have to hold their breath as they walk into a hospital emergency department due to the lack of appropriate personal protective equipment (PPE), as reported by one doctor in Seattle. ${ }^{5}$

Almost everyone saw the empty grocery store shelves in the beginning of the pandemic.

One person has an enormous amount of food stored in their pantry, while another has nothing. We never thought that in our lifetime we would see toilet paper being given as a gift on a birthday, a gesture that captured how difficult it was to find this basic supply at any store during the early phases of the pandemic. One person has a stockpile to last months, while another has none. As a clinician and leader at one U.S. hospital, it has been mind-blowing to experience the sudden disappearance of a medication called hydroxychloroquine when information emerged that it might help with COVID-19 symptoms. Many patients with lupus or rheumatoid arthritis depend on this medication to maintain their daily functions. Suddenly, many who do not need hydroxychloroquine stocked up, while those who required it were struggling to find it.

We are well-intended people, but fear can impede or even worsen our response to a crisis. The next time there is a crisis, let us keep in mind the next person and our neighbors. If 
there are only two items remaining, do not take both. If you do not need something, leave it for the next person who might need it more.

\section{Lesson number 2: We must rise to the occasion when faced with a crisis}

To face a crisis, we need to stay prepared. A hospital that treated the first known COVID-19 patient in the U.S. had conducted an elaborate pandemic preparedness drill weeks earlier. ${ }^{6}$ Once we learned about the potential for COVID-19 to reach our community, our hospital in Florida conducted a tabletop exercise consisting of various key players including law enforcement, Emergency Medical Services (EMS), physicians, nurses, pharmacists, respiratory therapists, and representatives from nearby hospitals. The planning group assessed various impacts of the virus on local hospitals and the community, and discussed collaboration efforts to respond to the pandemic. This assessment included how to expand space if the volume of patients is higher than the current bed capacity, how to ensure the acquisition of adequate supplies in anticipation of pandemic related shortages, and a discussion of details, such as how the pandemic would affect our employees with children if schools and daycares had to close.

Effective communication of quality information and well-informed decisions are crucial components of a crisis response. During a time when recommendations on how to respond to the pandemic are quickly evolving, we stay in constant contact with the CDC to learn about the latest updates on the nature of the virus and its treatment. We started a daily meeting with regional hospitals in our system to improve communication and ensure we are learning from each other. We discuss new studies and update our treatment for COVID-19 based on published evidence. For example, in the early days of the virus, some reports touted that a medication called lopinavir/ritonavir could be used, and, before we even had our first case, a new article was published showing no benefit of this medication in the treatment of COVID-19. ' As a result, our treatment guidance was updated to reflect the new conclusion.

Continuous reassessment of implemented actions and ongoing adjustment is critical. Af- ter dissecting all gathered data, we frequently update our treatment guidance and implement measures to both conserve PPEs and reduce the spread of the virus. A new role has emerged called PPE Czar, a person in charge of ensuring that PPEs are allocated appropriately. As information quickly becomes outdated, we continuously adapt our practice to what is best for our patients based on published evidence.

Collaboration is a necessity. Hospitals that used to compete with one another have started to collaborate during the pandemic. For example, two hospitals in New Jersey have shared masks, gowns, and ventilators during the crisis. ${ }^{8}$ HCA Healthcare provided as many as 1,000 ventilators to hospitals experiencing a surge of patients with COVID-19 as part of the collaboration between health systems, the federal government, and the American Hospital Association (AHA). ${ }^{9}$ Hospitals in Delaware are collaborating closely with each other to share information and resources and ensure a coordinated response to this pandemic. ${ }^{10}$

\section{Lesson number 3: We still have so much work to do as a society and we are counting on everyone to do their part}

During this pandemic, we have witnessed the best healthcare systems in the world struggle to find basic PPEs, such as face masks. We are experiencing a collapse of the best economies in the world in the wake of a circulating respiratory virus. The COVID-19 pandemic has brought to light the fact that we do not have everything figured out as a society. We all have different skills and gifts, and the world is desperately counting on us to use them to advance our society. During this crisis, many people are stepping up. It is heartening to see people sewing masks not only for themselves, but also for healthcare providers. In the midst of the mask shortage, a University of Florida Health doctor devised a way to make protective masks with once discarded wrapping materials used to keep surgical instruments sterile." We all need to step up and use our creativity to help the world. Once and for all, we should reject the victim mentality, and instead of sitting back and waiting to be saved, let us claim a seat at the table and give our contributions to mankind. 
Our generation has a chance to define how the world will look post COVID-19 pandemic. For anyone waiting for a wake-up call, this is it. We should not underestimate our contributions or wait for someone else to do it. The world can benefit from everyone's contribution. We should not waste any more time feeling sorry about our current or past situations or become paralyzed by inaction. The resilience of the human species is unquantifiable, and in the end we will win. Let us rise fearlessly to this occasion and keep the "we are in this together" spirit alive day by day. May love, kindness, and compassion be with us as we do our part.

\section{Conflicts of Interest}

The authors declare they have no conflicts of interest.

Dr. Manigaba is an employee of North Florida Regional Medical Center, an organization affiliated with the journal's publisher.

The views expressed in this publication represent those of the author(s) and do not necessarily represent the official views of HCA Healthcare or any of its affiliated entities.

\section{Author Affiliations}

1. Clinical Pharmacy Manager, North Florida Regional Medical Center, Gainesville, FL

2. PharmD Candidate 2021, University of Tennessee Health Science Center, College of Pharmacy, Memphis, TN

\section{References}

1. Associated Press. CLINTON IN AFRICA, Clinton's Painful Words of Sorrow and Chagrin. New York Times. March 26, 1998. https://www. nytimes.com/1998/03/26/world/clinton-in-africa-clinton-s-painful-words-of-sorrow-and-chagrin.html

2. SECRETARY-GENERAL, IN 'MISSION OF HEALING' TO RWANDA, PLEDGES SUPPORT OF UNITED NATIONS FOR COUNTRY'S SEARCH FOR PEACE AND PROGRESS. United Nations. Published May 6, 1998. https://www.un.org/ press/en/1998/19980506.SGSM6552.html

3. Hageman JC, Hazim C, Wilson K, et al. Infection Prevention and Control for Ebola in Health Care Settings - West Africa and United States. MMWR Suppl 2016;65(Suppl-3):50-56. http:// dx.doi.org/10.15585/mmwr.su6503a8

4. Institute of Medicine. Microbial Evolution and
Co-Adaptation: A Tribute to the Life and Scientific Legacies of Joshua Lederberg: Workshop Summary. The National Academies Press; 2009. https://doi.org/10.17226/12586

5. ER Doctor In Seattle, An Early COVID-19 Epicenter, On The Challenges Ahead. All Things Considered. National Public Radio. March 24, 2020. https://www.npr.org/2020/03/24/820957242/ er-doctor-in-seattle-an-early-covid-19-epicenter-on-the-challenges-ahead

6. Griwert K. How America's First Known Coronavirus Patient Recovered. FRONTLINE. Published online April 18, 2020. https://www. pbs.org/wgbh/frontline/article/how-americas-first-known-coronavirus-patient-recovered/

7. Cao B, Wang Y, Wen D, et al. A Trial of Lopinavir-Ritonavir in Adults Hospitalized with Severe Covid-19. N Engl J Med. 2020 Mar 18;382:17871799. https://doi.org/10.1056/NEJMoa2001282

8. How 1 New Jersey Hospital is Handling the Coronavirus Pandemic. Morning Edition. National Public Radio. April 15, 2020. https://www.npr. org/2020/04/15/834746377/how-1-new-jerseyhospital-is-handling-the-coronavirus-pandemic

9. HCA Healthcare provides ventilators to Dynamic Ventilator Reserve in battle against COVID-19. HCA Today. Published Apr 16, 2020. https://hcatodayblog.com/2020/04/16/hca-healthcare-provides-ventilators-to-battle-covid-19/

10. Delaware hospitals collaborate on COVID-19 response. Cape Gazette. April 30, 2020. https:// www.capegazette.com/article/delaware-hospitals-collaborate-covid-19-response/201338

11. Buletti L. UF Health anesthesiology team devises respirator mask made from existing hospital materials. UFHealth. Published March 26, 2020. https://ufhealth.org/news/2020/ uf-health-anesthesiology-team-devises-respirator-mask-made-existing-hospital-materials 